\title{
1 Do Intraplate and Plate Boundary Fault Systems Evolve in a Similar Way
}

\section{2 with Repeated Slip Events?}

3

\section{McKay ${ }^{a}$, R. J. Lunn ${ }^{\text {a }}$ Z. K. Shipton ${ }^{\text {a }}$, S. Pytharouli ${ }^{\text {a }}$ and J. J. Roberts ${ }^{\text {a }}$}

${ }^{a}$ Department of Civil and Environmental Engineering, University of Strathclyde, 75

Montrose Street, Glasgow, U.K., G1 1XJ

*Corresponding author: Lucy McKay (lucy.mckay@strath.ac.uk)

\section{Highlights}

- Geological evidence shows plate boundary (PB) \& intraplate faults evolve differently.

- PB faults are narrower and do not increase in width with increasing displacement.

- PB faults are narrow regardless of total slip events or local fault structure.

- We infer narrow PB faults do not process intact rock as much during seismic events.

- We infer PB faults dissipate less energy resulting in higher magnitude earthquakes.

\section{Abstract}

As repeated slip events occur on a fault, energy is partly dissipated through rock fracturing and frictional processes in the fault zone and partly radiated to the surface as seismic energy. Numerous field studies have shown that the core of intraplate faults is wider on average with increasing total displacement (and hence slip events). In this study we compile data on the fault core width, total displacement and internal structure (e.g., fault core composition, host rock juxtaposition, slip direction, fault type, and/or the number of fault core strands) of plate boundary faults to compare to intraplate faults (within the interior of tectonic plates). Fault core thickness data show that plate boundary faults are anomalously narrow by comparison to intraplate faults and that they remain narrow regardless of how much total displacement (hence 
26 how many earthquakes) they have experienced or the local structure of the fault. By examining

27 the scaling relations between seismic moment, average displacement and surface rupture length

28 for plate boundary and intraplate fault ruptures, we find that for a given value of displacement

29 in an individual earthquake, plate boundary fault earthquakes typically have a greater seismic

30 moment (and hence earthquake magnitude) than intraplate events. We infer that narrow plate

31 boundary faults do not process intact rock as much during seismic events as intraplate faults.

32 Thus, plate boundary faults dissipate less energy than intraplate faults during earthquakes

33 meaning that for a given value of average displacement, more energy is radiated to the surface

34 manifested as higher magnitude earthquakes. By contrast, intraplate faults dissipate more

35 energy and get wider as fault slip increases, generating complex zones of damage in the

36 surrounding rock and propagating through linkage with neighboring structures. The more

37 complex the fault geometry, the more energy has to be consumed at depth during an earthquake

38 and the less energy reaches the surface.

\section{Keywords}

41 Plate boundary faults; fault core; fault thickness; displacement; plate boundary fault internal

42 structure; earthquake energy balance 


\section{Introduction}

The earthquake energy balance as defined by Kanamori \& Anderson (1975; see also Kanamori \& Brodsky, 2001 and references therein) states that the total energy released during an earthquake is partly absorbed on the fault plane by fracturing and frictional dissipation and partly radiated out of the source as seismic waves. This can be expressed simply as equation(1):

$E_{T}=\left(E_{G}+E_{F}\right)+E_{R}$

where $E_{T}$ is the total energy released, $E_{G}$ is the fracture energy needed to create a new surface area, $E_{F}$ is the frictional energy required to slide along that surface and $E_{R}$ is radiated energy. Seismic data can be used to estimate $E_{G}$ and $E_{R}$ (from a power-law dependence with slip and from the seismic moment, respectively) but not $\mathrm{E}_{\mathrm{F}}$ (Shearer, 2009). From a geological perspective, when considering the processes active along faults during coseismic slip, $\mathrm{E}_{\mathrm{G}}$ and $E_{F}$ cannot be separated (Shipton et al., 2006a). This is because there are several physical processes that occur near the rupture front and in the surrounding rock (termed damage zone; Fig. 1) that involve frictional and/or fracture energy (Shipton et al., 2006a). These include gouge production, cataclasis, fracturing in the damage zone, the dissolution and growth of minerals and slip weakening mechanisms such as thermal pressurization or silica gel formation (e.g., Kirkpatrick and Shipton, 2009). All of these consume energy, preventing it radiating to the surface. Together, they are referred to as the dissipative energy $\left(E_{G}+E_{F}\right)$. During repeated slip events, energy will continue to be dissipated by these processes in the fault zone (both in the fault core and damage zone).

The physical processes that occur during rupture control the evolution of the fault over time, and hence with increasing total fault displacement. Compilations of data from multiple fault studies have shown that, on average, faults get wider as total displacement increases (e.g., Childs et al., 2009; Shipton et al., 2006b; Torabi et al., 2019; Van Der Zee et al., 2008; 
68 Wibberley et al., 2008), albeit with a large range in magnitude of width for a given displacement (Shipton et al 2006b). It is thought that this increase in width is due to the linkage of fault segments via relay formation and breaching (Childs et al., 2009, 2017; Fossen \& Rotevatn, 2016 and references therein; Fig. 1). That is, low displacement faults represent a stage of early growth and are thin but evolve into wide fault zones as they extend in length, link with adjacent faults and become more complex in structure. However, the vast majority of

74 the faults in these datasets are from intraplate settings (faults within the interior of tectonic plates and not the boundary of such plates).

77 The relationship between the total displacement on a fault and the evolution of fault core width 78 has not previously been explored for plate boundary faults, even though these are responsible 79 for $\sim 90 \%$ of global seismicity. Here, we compile and harmonise a global dataset of intraplate and plate boundary fault core width and total displacement data in order to examine whether

81 these fault systems evolve in a similar way with repeated slip events. Given the 82 interdependence between fault structure and earthquake processes (e.g., Kirkpatrick \& Shipton, 83 2009), we then examine the local structure (fault core composition, wall rock juxtapositions, 84 fault type and number of fault core stands) between all plate boundary faults in our dataset. 85 Further, we examine the scaling relations between seismic moment, average displacement and surface rupture length to compare estimates of radiated seismic energy for intraplate and plate

87 boundary fault events of the same average displacement. Finally, we infer how fault zone 88 processes could cause the systematic differences observed between plate boundary and intraplate fault systems. 
112 We use the same criteria to compile data for plate boundary faults, where the fault core refers to zones accommodating most of the strain across the fault. In total we find data for 75 sites on

11413 plate boundary faults. Our dataset combines our own field observations of the exhumed

\section{Methods}

We first compiled data on fault core width (as defined in Fig. 1) and total displacement from the peer-reviewed scientific literature. A fault is typically composed of one or more high-strain fault core(s) surrounded by an associated fractured damage zone (c.f. Caine et al., 1996; Fig. 1). We focus on the fault core because the majority of earthquake slip is accommodated by the core and the width is more easily constrained than the damage zone width (see Savage and Brodsky, 2011). As the classification method and terminology used to describe fault architecture can be ambiguous (Shipton et al., 2019), we developed an approach designed to harmonise the reported data to facilitate comprehensive comparison. To ensure consistency in our dataset, we only include studies where the width and composition (fault rock type) of the fault core are clearly defined and are reported as being distinct from the damage zone. Therefore, as in Torabi et al. (2019), we define the fault core width as the cumulative, acrossfault width of gouge, breccia, cataclasite, shale smear, lenses and/or diagenetic features on both sides of the fault (Fig. 1). If more than one fault core is described for a single fault zone, we estimate the fault core width as the total width of each of the fault core strands and not the collective width across multiple fault cores (i.e., the host rock entrained between the strands is not included in the width measurements). To ensure the definition of width is consistent, studies which report fault core width but provide no information on its composition are not included. Total displacement is measured from slip vector orientations and the separation of markers across the fault (Fig. 1).

$$
\text { Highland Boundary fault (McKay et al., 2020) with field and borehole studies of both modern }
$$


and ancient examples of plate boundary faults. These include the San Andreas fault

117 (Holdsworth et al., 2011; Moore and Rymer, 2012), North Anatolian fault (Dor et al., 2008),

118 Alpine fault (Barth et al., 2013; Toy et al., 2015), Carboneras fault (Faulkner et al., 2003),

119 Median Tectonic Line (Wibberley and Shimamoto, 2003), Nankai Trough (Ujiie and Kimura,

120 2014), Japan Trench (Kirkpatrick et al., 2015), Chelungpu thrust (Heermance et al., 2003; Yeh et al., 2007), Longmenshan thrust (Li et al., 2013) and ancient subduction boundaries from the compilation of Rowe et al. (2013). Where available, we include all reported data points along a single plate boundary fault to capture the spatial heterogeneity along-strike. Using this data, we then construct schematic structural logs to compare the local structure both along an individual plate boundary and between plate boundaries.

To complement our findings on intraplate and plate boundary fault widths, we gather data from the peer-reviewed scientific literature to examine earthquake scaling relations between intraplate and plate boundary fault events. We focus on the scaling relations between seismic moment, average displacement and surface rupture length. We extend the dataset of Scholz et al. (1986) by determining which earthquakes in the Wells \& Coppersmith (1994) dataset are plate boundary or intraplate fault events and by adding in examples from Wesnousky (2006; 2008). We separate the data based on fault type (plate boundary and intraplate fault events) and also by the method in which the seismic moment was determined (derived from seismological observations or from field observations). The calculation of seismic moment from field observations uses an estimate of the average fault displacement (Fig. 1). Since our aim is to investigate the relationship between seismic moment, average displacement and surface rupture length, our analyses focus on those events for which the seismic moment has been determined from the frequency spectrum of the recorded displacement (frequency spectrum analyses or moment tensor solutions). Thus, we ensure all measurements are independently 
derived and prevent a circular argument; no assumptions are made about the fault dimensions

142 in modelling the seismic energy release (seismic moment).

\section{3. Results}

145 3.1. Comparing Fault Core Width and Total Displacement for Intraplate and Plate

\section{Boundary Faults}

147 Like previous compilations (Childs et al., 2009; Shipton et al., 2006b; Torabi et al., 2019; Van

148 Der Zee et al., 2008; Wibberley et al., 2008), we obtain a statistically significant (p value 149 0.0004), positive power-law trend between fault core width and total displacement for 150 intraplate faults over several orders of magnitude (Fig. 2). In our dataset there are a higher number of lower displacement faults, perhaps reflecting the difficulty in identifying a reliable or preserved displacement marker for faults with larger total displacement. For this reason, the trendline underpredicts the width of larger displacement faults (displacement $>24 \mathrm{~m}$ ).

Based on the observed relationship for intraplate faults, plate boundary faults with large total displacement values $(>1000 \mathrm{~m})$ would be expected to have wide fault cores. However, we find plate boundary faults are distinct from the trend (Fig. 2). Instead, plate boundary faults are consistently narrow with fault core widths between $0.07 \mathrm{~m}$ and $\sim 35 \mathrm{~m}$ and there is no statistically significant ( $\mathrm{p}$ value 0.155 ) relationship with total displacement. This finding is regardless of either the fault type (strike-slip or convergent, there are no data for divergent boundaries) or the distance along-strike. Interestingly, whilst plate boundary faults are consistently 1-2 orders of magnitude narrower than would be predicted by the trend for intraplate faults, their variability along-strike is similar; the width of both intraplate and plate boundary faults ranges by 2-3 orders of magnitude for a single value of displacement on an 
individual fault. Therefore, despite plate boundary faults being consistently narrower, the along-strike variance in fault width is similar.

\subsection{Plate Boundary Fault Structure and Composition}

We could hypothesise that plate boundary fault cores are consistently narrower than intraplate faults because they have simple, uniform structures. To test this, we constructed schematic structural logs for each plate boundary exposure and drill core intersection reported in the published scientific literature. Fig. 3 shows a sub-set of these logs: the full set is available in the supplementary information (S2 and S3). Whilst all these plate boundary faults are narrow, their structures are not the same or simple. For example, the Highland Boundary fault (HBF) is a sinistral strike-slip fault with $115 \pm 85 \mathrm{~km}$ total displacement (McKay et al., 2020 and references therein). In all mapped exposures the fault core is a single strand that varies in width between 2.95 to $10.7 \mathrm{~m}$ (Fig. 3) (McKay et al., 2020). The host rocks remain constant alongstrike as the fault separates serpentinite from basement rocks at all exposures. In contrast, the fault core of the dextral strike-slip North Anatolian fault (NAF) remains narrow despite juxtaposing different host rock lithologies along-strike (Fig. 3) (Dor et al., 2008). Unlike the HBF and NAF, the Chelungpu thrust is a convergent boundary with a minimum of $14 \mathrm{~km}$ total displacement (Heermance and Evans, 2006). The fault principally slips within siliciclastic sedimentary rocks. At some exposures the fault core is composed of a single strand that varies in width between 0.07 to $1.77 \mathrm{~m}$ (Heermance et al., 2003; Yeh et al., 2007). At other exposures the fault core consists of a number of strands 0.1 to $2.45 \mathrm{~m}$ wide (Fig. 3 and S2 and S3) (Heermance et al., 2003; Yeh et al., 2007). Thus, the fact that plate boundaries are narrow appears not to be related to the host rock, slip directions, plate boundary type (strike-slip or convergent), distance along-strike or the number of fault strands. These all but the plate boundaries remain comparatively narrow. 
191 Based on this small dataset it may be the case that the fault core is narrowest when wall rocks of contrasting competencies juxtapose the fault, i.e., mechanically weak serpentinite against

193 basement or sedimentary rock, compared to basement against basement or sedimentary against 194 sedimentary with similar competencies. For example, the San Andreas fault is narrowest (0.15 m) when serpentinite juxtaposes sedimentary rocks (Moore and Rymer, 2012) and widest (9.1 m) when sedimentary rock juxtaposes sedimentary rock (Holdsworth et al., 2011) (Fig. 3). This suggests the strength contrast between the faulted layers (mechanical stratigraphy) may, in part, control the variations in fault core width along-strike, but it clearly does not control the average width.

\subsection{Comparing Intraplate and Plate Boundary Fault Earthquake Events}

To examine whether there is any evidence in the seismological literature for a difference in the energy emitted by intraplate and plate boundary faults we examined the scaling relations between seismic moment, average displacement and surface rupture length. Seismic moment $\left(\mathrm{M}_{0}\right)$ is a measure of the "size" or "work" of an earthquake (Bormann et al., 2013). It can be calculated from fault slip dimensions measured in the field or from aftershock distributions using the formula (equation(2)):

$208 M_{0}=\mu A D$

209 where, $\mu$ is the shear modulus, $\mathrm{A}$ is the event rupture area and $\mathrm{D}$ is the average displacement on the fault during coseismic rupture i.e. the average displacement caused by the individual seismic event (Fig. 1; Kanamori \& Anderson, 1975; Kanamori \& Brodsky, 2001).

212 Alternatively, it can be measured from the source spectra of body or surface waves (from the 213 integral of the far-field displacement, or from the amplitude of the near-field displacement) or 214 is derived from a moment tensor solution (Bormann et al., 2013). As such, calculating the 
seismic moment from spectral analyses is independent from average displacement. Whilst $\mathrm{M}_{0}$ is not a direct measure of energy, it is linearly related to the radiated seismic energy $\left(E_{R}\right)$ by

217 the formula (equation(3)):

$218 E_{R} \approx \eta_{R} \frac{\Delta \sigma_{S}}{2 \mu} M_{0}$

where, $\eta_{R}=\mathrm{E}_{\mathrm{R}} /\left(\mathrm{E}_{\mathrm{R}}+\mathrm{E}_{\mathrm{G}}\right)$ is radiated efficiency and $\Delta \sigma_{S}$ is the static stress drop, i.e., the difference between shear stresses on the fault before and after the earthquake (Bormann et al., 2013; Venkataraman \& Kanamori, 2004 and references therein). As stated in Kanamori \& Brodsky (2004), it is also linearly related to the magnitude $\left(\mathrm{M}_{\mathrm{w}}\right)$ by the formula (equation(4)):

$M_{w}=\left(\log M_{0}-9.1\right) / 1.5$

Thus, the higher the seismic moment, the higher the radiated seismic energy and the higher the magnitude of the resulting earthquake.

We find that for a given value of average displacement, plate boundary fault earthquakes typically have a greater seismic moment (Fig. 4a) and rupture a longer length at the surface (Fig. 4b) compared to intraplate faults. Our analyses show the best-fit line derived only from those events for which seismic moment has been derived from spectral analyses (as explained previously); however, for information, seismic events with field-derived seismic moments are also included on (Fig. 4) (unfilled symbols) and clearly show the same trends. These findings imply that plate boundary faults do not dissipate as much energy as intraplate faults during earthquakes meaning that for a given value of average displacement, more energy is radiated to the surface resulting in a greater seismic moment and hence a higher magnitude earthquake.

\section{Discussion}

For the first time fault core width and total displacement data have been compared for plate boundary and intraplate faults. We observe that the evolution of plate boundary faults is 
different to the more widely studied and better understood evolution of intraplate faults. Plate

241 boundary faults are anomalous when compared to the global population of intraplate faults;

242 they have narrower fault cores and the fault core width does not increase with increasing

243 displacement. Keren \& Kirkpatrick (2016) previously observed that the damage zone width of

244 the Japan Trench was anomalously narrow and did not follow the damage zone width to total 245 displacement trend described for intraplate faults (Mayolle et al., 2019 and references therein).

246 It may therefore be possible that a similar compilation of fault damage zone widths may also

247 show that plate boundary faults have anomalously narrow damage zones compared to intraplate

248 faults. This would make sense given plate boundary fault zone dissipate less energy (Fig. 4),

249 therefore less energy is available to crack the surrounding rock as much.

251 Scholz et al. (1986), state that intraplate fault cores are thin (gouge widths 1-10 m), whereas

252 plate boundary faults are wide (gouge width 100-1000 m) as a result of increased continuous dynamic wear of the wall rock with increased total displacement. However, no data are provided to back up their statement and our compilation of published data (Fig. 2) contradicts their proposition. Delogkos et al. (2020), suggest that all increases in fault zone width are the result of structural linkage and Power et al. (1988) show from experimental data that wall-rock wear switches off when a fault zone gets wide enough. From our compilation of plate boundary structures (Fig. 3), we suggest plate boundary fault cores are consistently narrow regardless of their structure. The fault core composition, host rock, slip direction, fault type, and/or the number of fault core strands all vary, both along an individual plate boundary and between plate boundaries, but in all examples the fault core remains consistently narrow. We suggest plate boundary faults remain narrow as they are not required to grow in the same way as intraplate faults. Plate boundary faults start as pre-existing, inherited structure on regional-scale zones of weakness. As such, their tips do not terminate within intact rock - they terminate at 
triple junctions with other plate boundaries (McKenzie and Morgan, 1969). As a result, they are not required to grow in length either by damaging intact rock at their tips or by linking with other pre-existing structures (as shown for intraplate faults in Fig. 1). The lack of linkage zones will tend to produce smoother structures. The lack of a relationship between fault zone width and total displacement on plate boundaries tends to support the hypothesis of Delogkos et al. (2020) for intraplate faults, i.e. that fault cores increase in width only due to progressive fault linkage, and that once they reach a sufficient width they can accommodate slip events without continuous processing of the wall rock - as appears to be the case for plate boundary faults.

Several authors have demonstrated that the more total displacement a fault accumulates, the smoother and straighter its surface geometry (e.g., Brodsky et al., 2011; de Joussineau \& Aydin, 2009; Sagy et al., 2007; Stirling et al., 1996; Wesnousky, 1988). Therefore, plate boundary faults with large total displacement values should be expected to have smooth and straight surface geometries as proposed by Wesnousky (1988). Using a combination of rock friction experiments and numerical modelling, Zielke et al. (2017) discuss the role of fault roughness on the stress drop and earthquake magnitude and postulate that smoother faults generate larger earthquakes compared to rougher faults under the same tectonic loading conditions. That is, faults with smoother surfaces do not need to consume as much energy to slip (i.e. dissipate less energy) compared to faults with rougher surfaces. The observations we present supports this hypothesis. Fig. $4 \mathrm{~b}$ demonstrates that for a given value of average displacement plate boundary faults rupture a longer length at the surface compared to intraplate faults. This implies that it may not be as easy to terminate a rupture on a plate boundary than on a rougher intraplate fault, which makes sense if they are narrow (Fig. 2), smooth (Wesnousky, 1988) and terminate at triple junctions and not within intact rock. Further, as demonstrated by the 1992 Landers earthquake, extra energy is required to hop over segments 
within faults (Hauksson et al., 1993). Therefore plate boundary faults, which are long structures not formed via fault linkage, will absorb less energy through segment hopping, allowing more energy to be radiated to the surface, manifested as higher magnitude earthquakes. By contrast, intraplate faults dissipate energy and get wider as fault slip increases, generating complex zones of damage in the surrounding rock and propagating through linkage with neighbouring structures (Fig. 1). The more complex the final fault geometry, the more energy has to be consumed at depth and the less energy reaches the surface (Ross et al., 2018).

\section{Conclusions}

Fault cores are well documented as getting wider and developing more complex geometries with increasing total displacement, albeit with a wide range in widths at a single value of displacement. This occurs through repeated rupture events which comminute fault slip surfaces and progressively fracture the surrounding intact rock at the fault tips and in a zone of damage that surrounds the fault. We have compiled data from the peer-reviewed literature to show that this relationship between fault core width and increasing displacement does not hold for plate boundary faults, which are anomalously narrow by comparison to intraplate faults and do not show the same trend of increasing average width with increasing displacement. From a compilation of plate boundary structures, we find plate boundary faults remain narrow regardless of how many earthquake events they have experienced or their local fault structure (fault core composition, host rock juxtaposition, slip direction, fault type, and/or the number of fault core strands). By examining the scaling relations between seismic moment, average displacement and surface rupture length for plate boundary and intraplate fault ruptures, we confirm that plate boundary faults display a greater seismic moment than intraplate faults for a given displacement and show that they also rupture a longer length. We propose that this occurs because plate boundary faults are anomalously narrow, they are comparatively smooth and 
315 terminate at triple and not intact rock, and since our data show they do not increase in width

316 with increasing displacement, they are not processing intact rock as much during seismic

317 events. Thus, plate boundary faults do not dissipate as much energy as intraplate faults during

318 earthquakes meaning that for a given value of average displacement, more energy is radiated

319 to the surface resulting in higher magnitude earthquakes.

320

321 Acknowledgements

322 This work is funded by an Environmental and Physical Science Research Council (EPSRC)

323 Doctoral Training Partnership (DTP) grant awarded to LM.

324

325 Supplementary Material/Data Statement

326 Data compiled in this study can be found in the supplementary information and is available

327 from the University of Strathclyde KnowledgeBase (data will be uploaded into the repository 328 after acceptance). 
329

330

331

332

333

334

335

336

337

338

339

340

341

342

343

344

345

346

347

348

349

350

351

352

353

\section{References}

Barth, N.C., Boulton, C., Carpenter, B.M., Batt, G.E., Toy, V.G., 2013. Slip localization on the southern Alpine Fault New Zealand. Tectonics 32, 620-640. https://doi.org/10.1002/tect.20041

Bormann, P., Wendt, S., Di Giacomo, D., 2013. Seismic Sources and Source Parameters, in: Bormann, P. (Ed.), New Manual of Seismological Observatory Practice 2 (NMSOP2). Deutsches GeoForschungsZentrum GFZ, Pastdam, pp. 1-259. https://doi.org/10.2312/GFZ.NMSOP-2_ch3

Brodsky, E.E., Gilchrist, J.J., Sagy, A., Collettini, C., 2011. Faults smooth gradually as a function of slip. Earth Planet. Sci. Lett. 302, 185-193. https://doi.org/10.1016/j.eps1.2010.12.010

Caine, J.S., Evans, J.P., Forster, C.B., 1996. Fault zone architecture and permeability structure. Geology 24, 1025-1028. https://doi.org/10.1130/0091-7613(1996)024<1025

Childs, C., Holdsworth, R.E., Jackson, C.A.-L., Manzocchi, T., Walsh, J.J., Yielding, G., 2017. Introduction to the geometry and growth of normal faults, in: Childs, C., Holdsworth, R.E., Jackson, C.A.-L., Manzocchi, T., Walsh, J.J., Yielding, G. (Eds.), The Geometry and Growth of Normal Faults. Geological Society London, Special Publications, 439, pp. 1-9. https://doi.org/10.1144/SP439.24

Childs, C., Manzocchi, T., Walsh, J.J., Bonson, C.G., Nicol, A., Schöpfer, M.P.J., 2009. A geometric model of fault zone and fault rock thickness variations. J. Struct. Geol. 31, 117-127. https://doi.org/10.1016/j.jsg.2008.08.009

de Joussineau, G., Aydin, A., 2009. Segmentation along Strike-Slip Faults Revisited. Pure Appl. Geophys. 166, 1575-1594. https://doi.org/10.1007/s00024-009-0511-4

Delogkos, E., Manzocchi, T., Childs, C., Camanni, G., Roche, V., 2020. The 3D structure of a normal fault from multiple outcrop observations. J. Struct. Geol. 136, 1-18. 
Dor, O., Yildirim, C., Rockwell, T.K., Ben-Zion, Y., Emre, O., Sisk, M., Duman, T.Y., 2008. Geological and geomorphologic asymmetry across the rupture zones of the 1943 and 1944 earthquakes on the North Anatolian Fault: possible signals for preferred earthquake propagation direction. Geophys. J. Int. 173, 483-504. https://doi.org/10.1111/j.1365-246X.2008.03709.x

Faulkner, D.R., Lewis, A.C., Rutter, E.H., 2003. On the internal structure and mechanics of large strike-slip fault zones: Field observations of the Carboneras fault in southeastern Spain. Tectonophysics 367, 235-251. https://doi.org/10.1016/S0040-1951(03)00134-3

Fossen, H., Rotevatn, A., 2016. Fault linkage and relay structures in extensional settings-A review. Earth Sci. Rev. 154, 14-28. https://doi.org/10.1016/j.earscirev.2015.11.014

Hauksson, E., Jones, L.M., Huiton, K., Eberhart-Phillips2, D., 1993. The 1992 Landers Earthquake Sequence: Seismological Observations, Journal of Geophysical Research. https://doi.org/10.1029/93JB02384

Heermance, R., Shipton, Z.K., Evans, J.P., 2003. Fault structure control on fault slip and ground motion during the 1999 rupture of the Chelungpu fault, Taiwan. Bull. Seismol. Soc. Am. 93, 1034-1050. https://doi.org/10.1785/0120010230

Heermance, R. V, Evans, J.P., 2006. Geometric evolution of the Chelungpu fault, Taiwan: the mechanics of shallow frontal ramps and fault imbrication. J. Struct. Geol. 28, 929938. https://doi.org/10.1016/j.jsg.2006.01.015

Holdsworth, R.E., Van Diggelen, E.W.E., Spiers, C.J., De Bresser, J.H.P., Walker, R.J., Bowen, L., 2011. Fault rocks from the SAFOD core samples: Implications for weakening at shallow depths along the San Andreas Fault, California. J. Struct. Geol. 33, 132-144. https://doi.org/10.1016/j.jsg.2010.11.010

Kanamori, H., Anderson, D.L., 1975. Theoretical Basin of Some Empirical Relations in 
379

380

381

382

383

384

385

386

387

388

389

390

391

392

393

394

395

396

397

398

399

400

401

402

403

Seismology. Bull. Seismol. Soc. Am. 65, 1073-1095.

Kanamori, H., Brodsky, E.E., 2004. The physics of earthquakes. Reports Prog. Phys. 67, 1429-1496. https://doi.org/10.1088/0034-4885/67/8/R03

Kanamori, H., Brodsky, E.E., 2001. The physics of earthquakes. Phys. Today 54, 34-40. https://doi.org/10.1063/1.1387590

Keren, T.T., Kirkpatrick, J.D., 2016. The damage is done: Low fault friction recorded in the damage zone of the shallow Japan Trench decollement. J. Geophys. Res. Solid Earth 131, 3804-3824. https://doi.org/10.1002/2015JB012311

Kirkpatrick, J.D., Rowe, C.D., Ujiie, K., Moore, J.C., Regalla, C., Remitti, F., Toy, V., Wolfson-schwehr, M., Kameda, J., Bose, S., Chester, F.M., 2015. Structure and lithology of the Japan Trench subduction plate boundary fault. Tectonics 34, 53-69. https://doi.org/10.1002/2014TC003695

Kirkpatrick, J.D., Shipton, Z.K., 2009. Geologic evidence for multiple slip weakening mechanisms during seismic slip in crystalline rock. J. Geophys. Res. 114, 1-14. https://doi.org/10.1029/2008JB006037

Li, H., Wang, H., Xu, Z., Si, J., Pei, J., Li, T., Huang, Y., Song, S.R., Kuo, L.W., Sun, Z., Chevalier, M.L., Liu, D., 2013. Characteristics of the fault-related rocks, fault zones and the principal slip zone in the Wenchuan Earthquake Fault Scientific Drilling Project Hole-1 (WFSD-1). Tectonophysics 584, 23-42. https://doi.org/10.1016/j.tecto.2012.08.021

Mayolle, S., Soliva, R., Caniven, Y., Wibberley, C., Ballas, G., Milesi, G., Dominguez, S., 2019. Scaling of fault damage zones in carbonate rocks. J. Struct. Geol. 124, 35-50. https://doi.org/10.1016/j.jsg.2019.03.007

McKay, L., Shipton, Z.K., Lunn, R.J., Andrews, B., Raub, T.D., Boyce, A.J., 2020. Detailed Internal Structure and Along-Strike Variability of the Core of a Plate Boundary Fault: 
404

405

406

407

408

409

410

411

412

413

414

415

416

417

418

419

420

421

422

423

424

425

426

427

428

The Highland Boundary Fault, Scotland. J. Geol. Soc. London 177, 283-296. https://doi.org/https://doi.org/10.1144/jgs2018-226

McKenzie, D.P., Morgan, W.J., 1969. Evolution of Triple Junctions. Nature 224, 125-133.

Moore, D.E., Rymer, M.J., 2012. Correlation of clayey gouge in a surface exposure of serpentinite in the San Andreas Fault with gouge from the San Andreas Fault Observatory at Depth (SAFOD). J. Struct. Geol. 38, 51-60. https://doi.org/10.1016/j.jsg.2011.11.014

Power, W.L., Tullis, T.E., Weeks, J.D., 1988. Roughness and Wear During Brittle Faulting. J. Geophys. Res. 93, 15268-15278. https://doi.org/10.1029/JB093iB12p15268

Ross, Z.E., Kanamori, H., Hauksson, E., Aso, N., 2018. Dissipative Intraplate Faulting During the 2016 M w 6.2 Tottori, Japan Earthquake. J. Geophys. Res. Solid Earth 123, 1631-1642. https://doi.org/10.1002/2017JB015077

Rowe, C.D., Moore, J.C., Remitti, F., 2013. The thickness of subduction plate boundary faults from the seafloor into the seismogenic zone. Geology 41, 991-994. https://doi.org/10.1130/G34556.1

Sagy, A., Brodsky, E.E., Axen, G.J., 2007. Evolution of fault-surface roughness with slip. Geology 35, 283-286. https://doi.org/10.1130/G23235A.1

Savage, H.M., Brodsky, E.E., 2011. Collateral damage: Evolution with displacement of fracture distribution and secondary fault strands in fault damage zones. J. Geophys. Res. 116, 1-14. https://doi.org/10.1029/2010JB007665

Scholz, C.H., Aviles, C.A., Wesnousky, S.G., 1986. Scaling differences between large interplate and intraplate earthquakes. Bull. Seismol. Soc. Am. 76, 65-70.

Shearer, P.M., 2009. Introduction to Seismology, 2nd ed. Cambridge University Press, Cambridge.

Shipton, Z.K., Evans, J.P., Abercrombie, R.E., Brodsky, E.E., 2006a. The Missing Sinks: Slip 


\section{Localization in Faults, Damage Zones, and the Seismic Energy Budget, in:} Abercrombie, R., McGarr, A., Di Toro, G., Kanamori, H. (Eds.), Earthquakes: Radiated Energy and the Physics of Faulting, Geophysical Monograph Series 170. American Geophyscial Union, Washington D.C., pp. 217-222. https://doi.org/10.1029/170GM22

Shipton, Z.K., Roberts, J.J., Comrie, E.L., Kremer, Y., Lunn, R.J., Caine, J.S., 2019. Fault fictions: cognitive biases in the conceptulization of faults zones, in: Ogilvie, S., Urai, J.L., Dee, S., Wilson, R.W., Bailey, W. (Eds.), Integrated Fault Seal Analysis. Geological Society London, Special Publications 496. https://doi.org/10.1144/SP4962018-161

Shipton, Z.K., Soden, A., Kirkpatrick, J.D., Bright, A.M., Lunn, R.J., 2006b. How thick is a fault? Fault displacement thickness scaling revisited, in: Abercrombie, R., McGarr, A., Di Toro, G., Kanamori, H. (Eds.), Earthquakes: Radiated Energy and the Physics of Faulting, Geophysical Monograph Series 170. American Geophysical Union, Washington D.C., pp. 193-198. https://doi.org/10.1029/170GM19

Stirling, M.W., Wesnousky, S.G., Shimazaki, K., 1996. Fault trace complexity, cumulative slip, and the shape of the magnitude-frequency distribution for strike-slip faults: A global survey. Geophys. J. Int. 124, 833-868. https://doi.org/10.1111/j.1365246X.1996.tb05641.x

Torabi, A., Johannessen, M.U., Ellingsen, T.S.S., 2019. Fault Core Thickness: Insights from Siliciclastic and Carbonate Rocks. Geofluids 1-24. https://doi.org/10.1155/2019/2918673

Toy, V.G., Boulton, C.J., Sutherland, R., Townend, J., Norris, R.J., Little, T.A., Prior, D.J., Mariani, E., Faulkner, D., Menzies, C.D., Scott, H., Carpenter, B.M., 2015. Fault rock lithologies and architecture of the central Alpine fault, New Zealand, revealed by DFDP-1 drilling. Lithosphere 7, 155-173. https://doi.org/10.1130/L395.1 
Ujiie, K., Kimura, G., 2014. Earthquake faulting in subduction zones: insights from fault rocks in accretionary prisms. Prog. Earth Planet. Sci. 1, 1-30. https://doi.org/10.1186/2197-4284-1-7

Van Der Zee, W., Wibberley, C.A.J., Urai, J.L., 2008. The influence of layering and preexisting joints on the development of internal structure in normal fault zones: the Lodève basin, France, in: Wibberley, C.A.J., Kurz, W., Imber, J., Holdsworth, R.E., Collettini, C. (Eds.), The Internal Structure of Fault Zones: Implications for Mechanical and Fluid-Flow Properties. Geological Society London, Special Publications 299, pp. 57-74. https://doi.org/10.1144/SP299.4

Venkataraman, A., Kanamori, H., 2004. Observational constraints on the fracture energy of subduction zone earthquakes. J. Geophys. Res. Solid Earth 109, 1-20. https://doi.org/10.1029/2003JB002549

Wells, D.L., Coppersmith, K.J., 1994. New empirical relationships among magnitude, rupture length, rupture width, rupture area, and surface displacement. Bull. Seismol. Soc. Am. $84,974-1002$.

Wesnousky, S.G., 2008. Displacement and Geometrical Characteristics of Earthquake Surface Ruptures: Issues and Implications for Seismic-Hazard Analysis and the Process of Earthquake Rupture. Bull. Geol. Soc. Am. 98, 1609-1632. https://doi.org/10.1785/0120070111

Wesnousky, S.G., 2006. Predicting the endpoints of earthquake ruptures. Nature 444, 358360. https://doi.org/10.1038/nature05275

Wesnousky, S.G., 1988. Seismological and structural evolution of strike-slip faults. Nature 335, 340-343. https://doi.org/10.1038/335340a0

Wibberley, C.A.J., Shimamoto, T., 2003. Internal structure and permeability of major strikeslip fault zones: The Median Tectonic Line in Mie Prefecture, Southwest Japan. J. 
480 Wibberley, C.A.J., Yielding, G., Di Toro, G., 2008. Recent advances in the understanding of 481 fault zone internal structure: a review, in: Wibberley, C.A.J., Kurz, W., Imber, J., 482 Holdsworth, R.E., Collettini (Eds.), Geological Society, London, Special Publications. $483 \quad$ pp. 5-33. https://doi.org/10.1144/SP299.2

484 Yeh, E.C., Sone, H., Nakaya, T., Ian, K.H., Song, S.R., Hung, J.H., Lin, W., Hirono, T., 485 Wang, C.Y., Ma, K.F., Soh, W., Kinoshita, M., 2007. Core description and 486 characteristics of fault zones from Hole-A of the Taiwan Chelungpu-Fault Drilling 487 Project. Terr. Atmos. Ocean. Sci. 18, 327-357.

$488 \quad$ https://doi.org/10.3319/TAO.2007.18.2.327(TCDP)

489 Zielke, O., Galis, M., Mai, P.M., 2017. Fault roughness and strength heterogeneity control 490 earthquake size and stress drop. Geophys. Res. Lett. 44, 777-783.

491 https://doi.org/10.1002/2016GL071700 


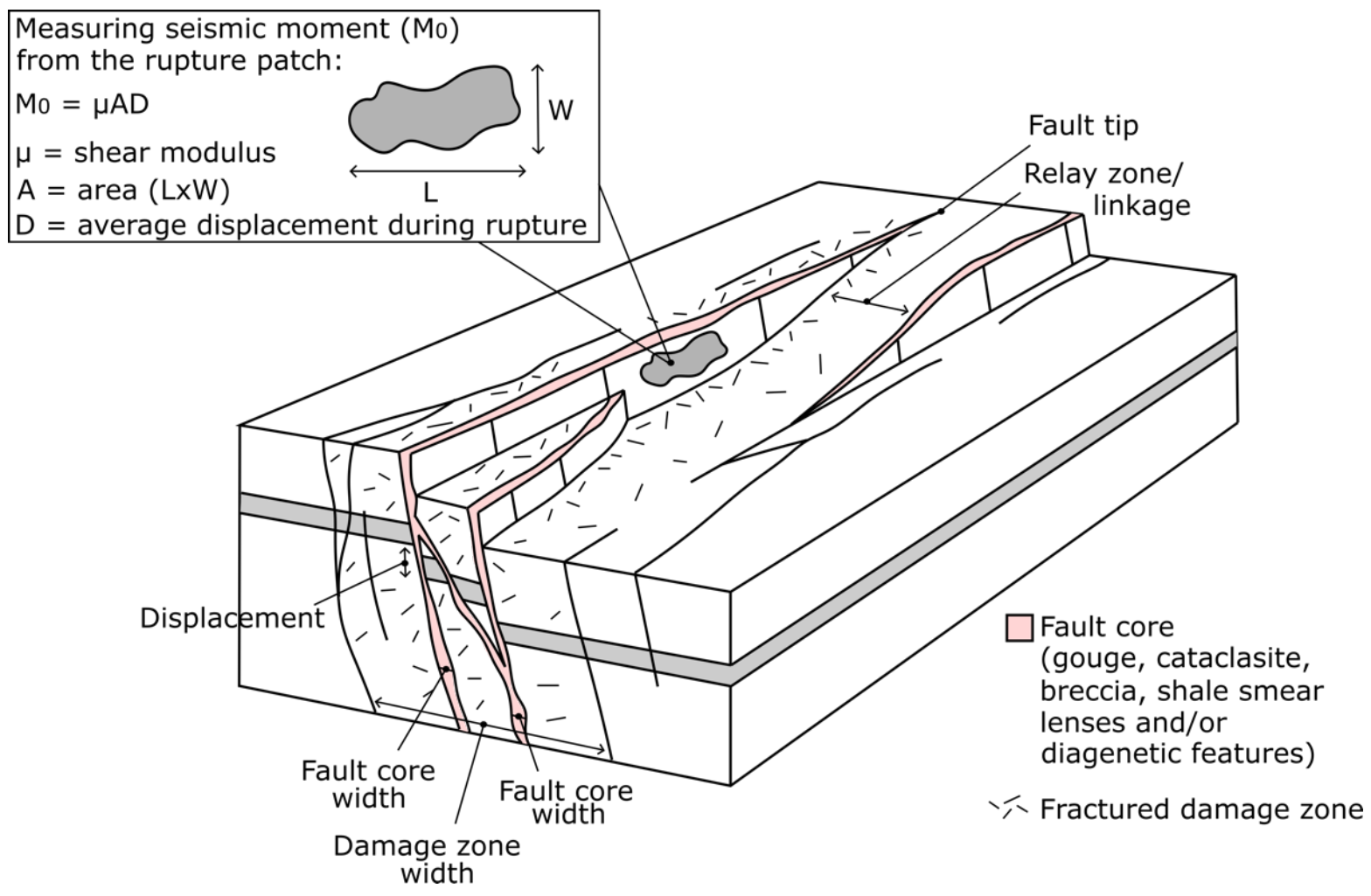

Fig. 1. Schematic diagram comparing the terms used in this paper with the typical fault core/damage zone fault structure. Figure modified from Childs et al. (2009).

Double column figure; colour in print 


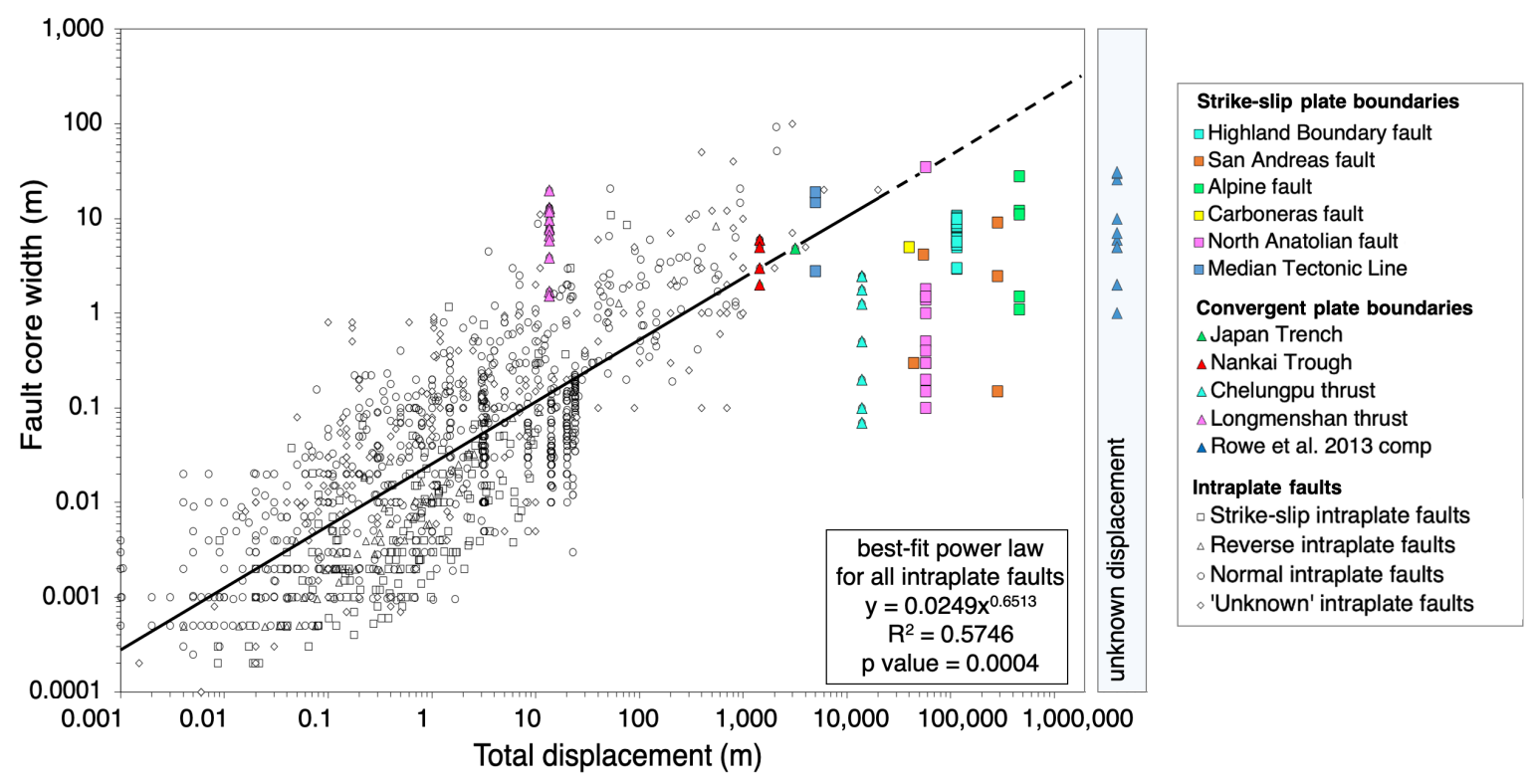

Fig. 2. Log-log plot of fault core width and total displacement for intraplate (greyscale) and plate boundary (colour) faults. The trendline shows the linear, statistically significant ( $p$ value 0.0004 ) relationship between fault core width and total displacement for intraplate faults and is extrapolated to large displacement values. There is no trend for plate boundary faults ( $p$ value 0.155). Displacement is unknown for the data in the Rowe et al. (2013) compilation due to a lack of preserved displacement markers. Strike-slip faults are represented by squares, reverse/thrust faults by triangles, normal faults by circles and an unknown sense of motion by diamonds. See the Supplementary Information for a description and sources of all data. 


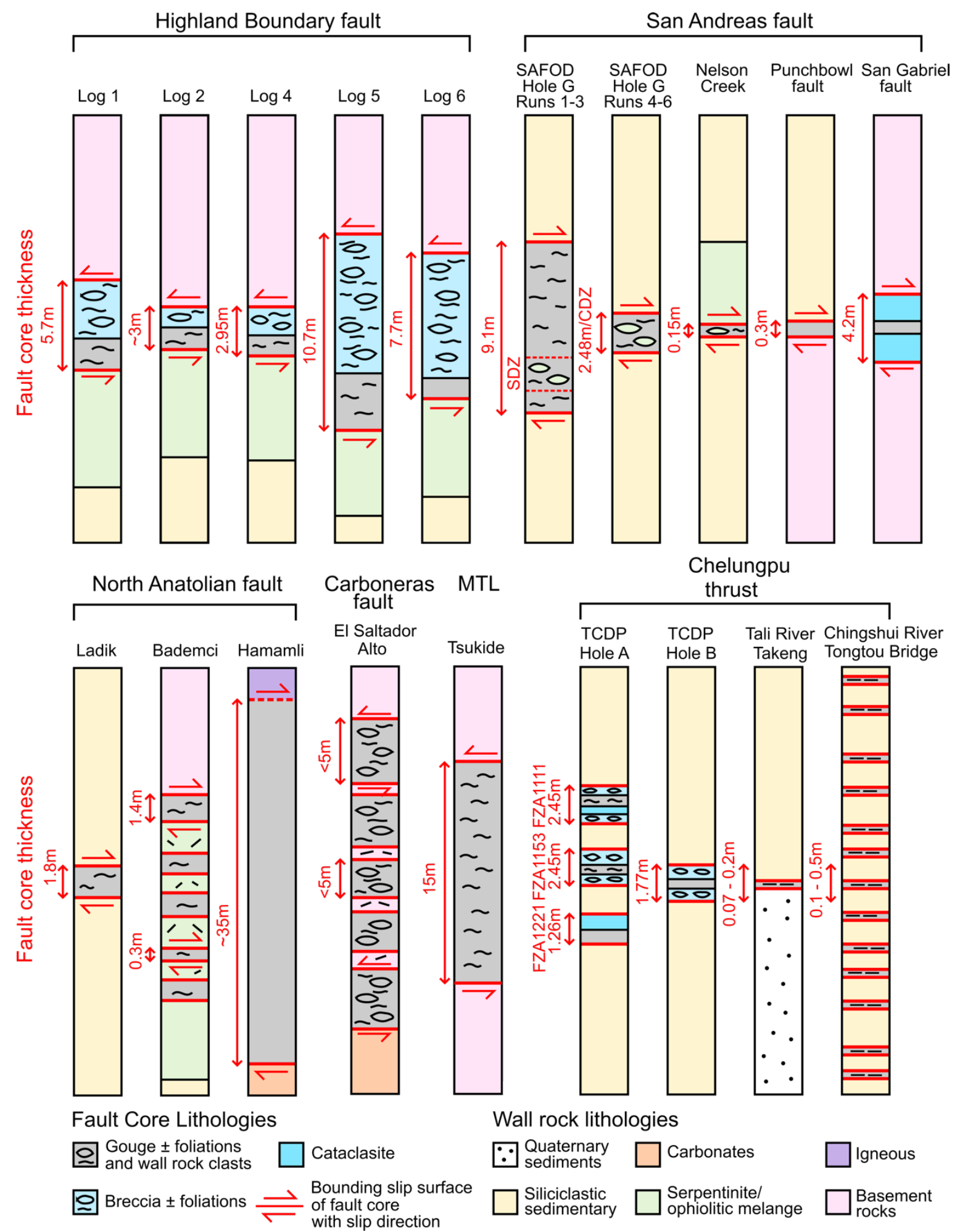

Fig. 3. Schematic structural logs illustrating fault core width and composition for plate

boundary faults. MTL, Median Tectonic Line. See Supplementary Information for the full set of Logs and data. Full page figure; colour in print 

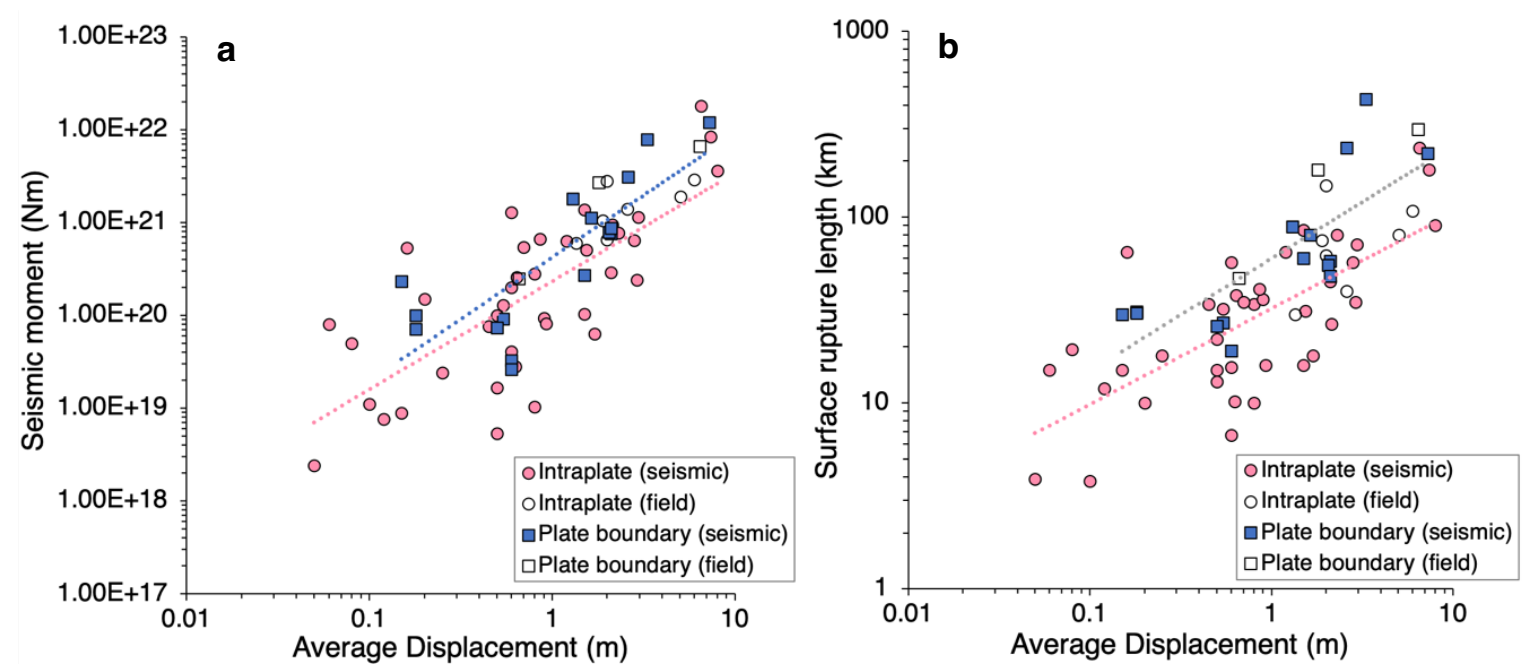

Fig. 4. Comparing intraplate and plate boundary fault earthquake events. a) Log-log plot of average displacement against seismic moment. We separate the data based on fault type (plate boundary fault - squares; intraplate faults - circles) and also the method in which the seismic moment was determined (derived from seismological data - colour; derived from field data - unfilled). We only show the best-fit line where the seismic moment has been derived from seismological data as the axes are truly independent. The fit line colour matches data points (blue - plate boundary; pink - intraplate events). b) Log-log plot of average displacement and surface rupture length of the fault associated with the earthquake event. The average displacement is not available for all events; therefore, the plots do not show exactly the same events.

\section{Double column figure; colour in print}

